\title{
Research on Rural Industrial Structure Adjustment and Agricultural Economic Development
}

\author{
Zhang Xuqi \\ Xi'an International University, Business School 710077, China
}

Keywords: rural industrial structure adjustment, agricultural economic development

\begin{abstract}
Due to backward technology, fragmented farmland, and low labor quality, China's agricultural industry structure has been irrational, which has severely inhibited the growth of the agricultural economy, resulting in slower growth of farmers' income and lagging behind in rural development. By rationally adjusting and optimizing the agricultural industrial structure, it is required to promote the rapid growth of the agricultural economy and open up a new path for solving the "three rural issues."
\end{abstract}

\section{Introduction}

Since ancient times, agriculture has occupied a very important position in the development of our country. In the process of China's modernization, the issue of "agriculture, rural areas and farmers" is also a long-term problem. After the reform and opening up, China's agricultural economic structure has undergone tremendous changes. In the past, agricultural products were in short supply, and now they are gradually developing into oversupply, but they have also created problems and contradictions. It is imperative to adjust the traditional agricultural economic structure. Through analyzing the problems existing in China's agricultural economic structure, we will explore effective countermeasures to promote the development of agricultural economic structure, propose advanced experience in absorbing foreign agricultural development, give full play to the advantages of China's agricultural production, fundamentally increase the average income of farmers, and promote China's agricultural economy.

Agriculture is the foundation of national stability. It is the most important aspect of China's development and the foundation of industrial development. China is the most populous country in the world. The demand for food is very large. Only grain is self-sufficient, and the stable development of agricultural economy is ensured. Only in the event of a crisis can we ensure social stability and ensure that the entire national economy is not affected. In the development practice, it is necessary to constantly adjust the structure of China's agricultural economy in light of specific circumstances and promote the rapid development of agriculture. This article mainly analyzes the status quo of China's agricultural economic structure. According to the main problems existing in the development process, it proposes effective ways to reform the agricultural economic model and injects new impetus into the future development of agricultural economy.

\section{Related Research on the Adjustment of Agricultural Industrial Structure}

As a primary industry, agriculture is an indispensable and irreplaceable industrial sector for the development of the national economy and people's lives. As an industrial structure that reflects the composition of industries with the same characteristics and economic activities in agriculture, and their interrelation and proportional relationship, it directly affects the development of agriculture and even the entire national economy. Researching agricultural economy from different angles has its unique value. The current researchers have defined the adjustment of agricultural industrial structure mainly as follows: Some scholars believe that the structural adjustment of agricultural industry includes the adjustment of industrial structure, In the adjustment of regional structure and adjustment 
of social structure, they emphasized that we must pay attention to the analysis of the socio-economic environment of the adjustment of the industrial structure of the agricultural industry in the new stage, and seek a way out for agriculture from the institutional and policy environment for agricultural development; there are also scholars that The adjustment of agricultural industrial structure includes two levels of structural adjustment within agriculture, which refers to the internal structure of the four sectors of plantation, forestry, animal husbandry and fishery and their interrelationships; some scholars believe that the adjustment of agricultural industrial structure It includes not only the internal structural adjustment of agriculture but also the external structure of agriculture, which is mainly related to the structural adjustment of the secondary and tertiary industries, and has a major relationship with these two industries; some scholars believe that the agricultural industrial structure only refers to The proportional relationship between quality and quantity across industries in the farming industry. The restructuring of the agricultural industry described in this paper mainly refers to the adjustment of the four major industries of crop farming, forestry, animal husbandry, and fisheries within the agriculture. Under different location choices, how to adjust the relationship between the four major industries can make the economic benefits Maximize.

The research on the optimization of the agricultural industry structure began in the 1980s. Many scholars later studied and discussed this issue from different perspectives. Theoretical Basis for Agricultural Industrial Structure Adjustment Research, Xu Xiang et al. believe that the theoretical basis for the adjustment of agricultural industrial structure is the theory of comparative advantage and factor endowment, insisting on the use of local comparative advantages, and rationally adjusting the industrial structure of agriculture in order to promote the formation of industrial comparisons. Zhang Jiuhan summarized the theoretical basis for the adjustment of agricultural industrial structure as the hypothesis of domestic market demand, the hypothesis of foreign market trade, and the hypothesis of alternative to scientific and technological innovation. It demonstrated that the structure of agricultural industry needs to be adjusted, and that agricultural structural adjustment is the growth factor of agricultural economy. It is resource reconfiguration.

Although some scholars have studied the problems of China's agricultural structural adjustment, western agricultural development, and peasant income increase, there are many deficiencies in the existing research: First, the results of agricultural structural adjustment studies lack strong data support, and most of them are only based on subjective judgments. On the basis of the second; empirical research is less, qualitative analysis, normative analysis, even if it is empirical analysis, the research method is too singular; in addition, the previous research did not consider the relationship between agriculture and the environment. Therefore, it is of great theoretical and practical significance to study the impact of agricultural restructuring in China's western regions on farmers' income and energy efficiency. The innovation of this paper is to use the provincial panel data of western China to establish a fixed effect model to examine the overall impact of the adjustment of western rural industrial structure on peasants' income, and further establish a variable coefficient model to measure the effects of the adjustment of industrial structure in western provinces on peasants' income increase. In addition, taking into account the relationship between industrial orientation and adjustment of industrial structure and energy efficiency in western rural areas, some relationships between the western agricultural industrial structure and energy efficiency are also discussed through panel data modeling, and good results have been obtained.

\section{Problems in China's Agricultural Economic Structure}

First, the agricultural economy is relatively weak and productivity is low. The tilting policy on the allocation of resources in our country has led to a relatively slow development of the agricultural economy. Due to the relatively small investment in rural areas, the aging of equipment itself is serious, and a sound agricultural infrastructure has not yet been formed. In some places, basic equipment is very backward and it is simply not suitable for the development of modern agriculture. China's agriculture has always maintained a family-oriented development, mainly reflected in the 
backwardness of agricultural technology and the low level of industrial production. The relatively weak economic foundation has dampened the enthusiasm of the farmers and hindered the development of the agricultural economy.

Second, the quality of rural labor needs to be improved, and the transfer of surplus labor is not going smoothly. The proportion of rural population in China is relatively large, and there are many surplus laborers. Supply exceeds demand, which has a certain impact on the development of agricultural economy. Quasi-exchange is a relatively complicated issue. The solution of surplus labor force has become an important link in the development of agricultural economy. . The transfer of surplus rural labor in our country is mainly accomplished through rural industry or working in cities. However, the actual situation of China's rural surplus labor is lower professional skills and the overall quality is not high, which also increases the difficulty of labor transfer.

Third, the structure of agricultural product supply and demand is not balanced, and the quality rate is relatively low. There is no obvious local feature. With the increase of China's comprehensive agricultural production capacity, the situation of oversupply of agricultural products has already formed, and even a large number of stocks have been unmarketable. There are many varieties of agricultural products in China, such as fruit products, meat products, and flower products, but in the international market, they are faced with problems such as low quality and unsatisfactory varieties. The localities have not yet brought into full play the advantages of their own regions. The adjustment of the agricultural industry structure is not balanced. On the whole, there is still no regional distribution of agricultural products with distinctive local characteristics.

Fourth, the rural resources are in poor condition and the agricultural ecological environment is poor. China's rural economic development has been affected by the poor resource situation. In the past, China's agricultural development has been dominated by extensive economic growth. With the increase of China's population, urbanization has accelerated, land resources have gradually decreased, and arable land has been greatly reduced. , resulting in a huge pressure on the environment, resulting in the waste of resources. Due to the large amount of resources consumed in previous agricultural development, land pollution problems are serious, and geological disasters and water pollution often occur.

\section{The Rural Industrial Structure Adjustment Promotes the Development of Agricultural Economy}

The adjustment of the agricultural industry structure has aroused the attention of domestic scholars because of the important issues concerning the social stability in rural areas, the development of agricultural economy, and the increase in peasants' income. This article defines the study as a question of structural optimization related to the internal level of agriculture. Through panel data modeling, the impact of the adjustment of the agricultural industry structure in rural areas of western China on the increase in income of farmers is examined in terms of overall and regional differences. With regard to the relationship between energy efficiency and energy efficiency, we should explore the desirable direction of agricultural restructuring to balance rural economy, energy and the environment and strive for harmonious development. From the results of the study, the government should increase investment in western agriculture and promote technological innovation. The government can only increase investment in the construction of the western agricultural infrastructure, play a guiding role, continuously improve the production conditions of agriculture, and give full play to the comprehensive production capacity of agriculture so as to better optimize the structure of the agricultural industry, increase the degree of peasant organization, and develop agricultural products. Other major conclusions and policy recommendations are:

First of all, in measuring the impact of the restructuring of the agricultural industry on the income of farmers, it was found that, as a whole, the effect of planting and forestry on the increase of farmers' income in the western region was negative, while animal husbandry and fishery could increase the income of farmers; From a regional point of view, animal husbandry promotes rural residents in Inner 
Mongolia to increase their income, while agriculture plays an inhibitory role; Guangxi plays a positive role in fisheries and agroforestry plays a negative role; in Sichuan and Chongqing, as a whole, agroforestry also has a negative effect on farmers' income. The animal husbandry and fishery have a significant positive impact on farmers' income, especially fisheries. According to the model results, the fishery output value increased by $1 \%$, and farmers' income can increase by $3.69669 \%$. In addition, the fishery has an even greater effect on farmers' income in Qinghai. Therefore, such areas have vigorously developed fisheries to increase output value and thus promote agricultural development; however, the impact of fisheries on farmers' income in Guizhou, Yunnan, and Xinjiang has been significantly negative. At this time, production should be reduced to a certain extent, and investment in other industries should be promoted. For example, Xinjiang can focus on the development of forestry to increase the income of farmers. The western region should adjust measures to local conditions and based on giving full play to local resource advantages, adjust the structure of the agricultural industry, develop local agricultural ecosystems that suit local characteristics according to its own characteristics and market demand, adhere to the coordinated development of regional agriculture, and optimize the allocation of agricultural resources among regions. This will increase farmers' income and narrow the gap between urban and rural areas. Second, relative to the secondary and tertiary industries, the relationship between agricultural industrial structure and energy efficiency is not very significant, but for the rural areas in the western part of the country based on agriculture, to explore the relationship between the two can still find the existing problems. As a whole, only western animal husbandry has a positive effect on energy efficiency in the rural areas of the western region; from a regional point of view, the structural adjustment of the agricultural industry does not play a role in improving energy efficiency in all regions. The results of the study indicate that the restructuring of the agricultural industry in Inner Mongolia, Guangxi, and Xinjiang has no significant effect on the change in energy efficiency, but in the regions where there is an impact, these four industries are also negatively correlated with energy efficiency.

Once again, combining the aforementioned conclusions and considering changes in the structure of the agricultural industry, increasing farmers' income, and energy efficiency, we found that adjustments in the four industries of agriculture, forestry, animal husbandry and fishery have significant effects on farmers' income and energy efficiency in different regions. Farmers' income and energy efficiency have changed in the same direction. The increase in the proportion of the output value of Ningxia's animal husbandry can simultaneously increase the income and energy efficiency of farmers. This is also true in Qinghai's forestry industry; but if the proportion of animal husbandry in Yunnan Province's output value increases, farmers' income and energy efficiency will be inhibited, and agriculture in Sichuan and Chongqing will also increase. Face the same situation. These are issues that government authorities may need to pay attention to. The sustainable development of agriculture is a new mode of agricultural development that seeks coordinated development of population, resources, environment and economy. The western region should adjust the agricultural structure, protect the ecological environment and achieve the sustainable development of agriculture in the western region under the established population pressure and agricultural resources. .

\section{Conclusion}

A concrete analysis of the current situation of China's agricultural economic structure was conducted, and the existing problems and causes of the problems were found. Effective solutions were proposed in light of actual conditions. We must dare to open the agricultural market, introduce advanced foreign agricultural technologies, and adjust and optimize agriculture. Economic structure gives full play to the advantages of China's agricultural products, formulate scientific and effective policies, and establish and improve relevant systems for agricultural development. With the support of the government's policies, we will increase the construction of agricultural infrastructure, promote the development of China's agriculture in a multi-functional, diversified and integrated manner, and promote the optimization and upgrading of our country's agricultural structure. 


\section{References}

[1] B. N. Ma, The state government procurement management system, J. Chinese Financial Information. 44 (2010) 146-147.

[2] H.X.Zeng, The dilemma faced by China's government procurement and countermeasures, J. Trade Finance. 18(2005) 55-57.

[3] J.H.Xue, Establishing government procurement system initial ideas, J. Coastal Economy, 32(2012) 189-190.

[4] Y.J.Qi, Government procurement system: international experience and reference, J, China Reform, 4(2007) 38-40.

[5] Y.M.Tian, International comparison of government procurement system and implications for China, J. Theorists, 9(2013) 142-150. 